\title{
Diagnosis of bile duct cancer by bile cytology: usefulness of post-brushing biliary lavage fluid
}

Authors

Institutions
Shinya Sugimoto ${ }^{1}$, Hiroyuki Matsubayashi ${ }^{1}$, Hirokazu Kimura² ${ }^{2}$ Keiko Sasaki ${ }^{3}$, Kaori Nagata ${ }^{3}$, Sachiyo Ohno ${ }^{3}$, Katsuhiko Uesaka ${ }^{4}$, Keita Mori ${ }^{5}$, Kenichiro Imai ${ }^{1}$, Kinichi Hotta ${ }^{1}$, Kohei Takizawa ${ }^{1}$, Naomi Kakushima', Masaki Tanaka', Noboru Kawata ${ }^{1}$, Hiroyuki Ono

Institutions are listed at the end of article. submitted 21. October 2014 accepted after revision 31. October 2014

\section{Bibliography}

Dol http://dx.doi.org/ 10.1055/s-0034-1391666 Published online: 7.5.2015 Endosc Int Open 2015; 03: E323-E328

(C) Georg Thieme Verlag KG Stuttgart . New York E-ISSN 2196-9736

\section{Corresponding author} Hiroyuki Matsubayashi, MD, PhD

Division of Endoscopy Shizuoka Cancer Center 1007 Shimonagakubo, Nagaizumi, Suntogun Shizuoka 411-8777 Fax: Japan+81-55-989-5692 h.matsubayashi@scchr.jp
Background: Pathologic evidence of biliary diseases can be obtained from cytology in addition to endoscopic retrograde cholangiopancreatography (ERCP); however, the diagnostic effectiveness is not satisfactory.

Study aim: This retrospective, single-center study evaluated the efficacy of various sampling methods for the cytologic diagnosis of bile duct cancer. Patients and methods: Biliary samples included bile that was simply aspirated, brush smear, brush-rinsed saline, and post-brushing biliary lavage fluid. A set of samples was compared for cytologic efficacy in 76 patients with surgically proven bile duct cancer and in 50 patients with benign biliary stricture.

Results: The cytologic sensitivity for diagnosing biliary cancer was 34\% with aspirated bile, 32\% with brush smear, $43 \%$ with brush-rinsed saline, and $70 \%$ with post-brushing biliary lavage fluid, in contrast to the null false-positive result in the

\section{Introduction}

\section{$\nabla$}

Several disorders are involved in the etiology of bile duct strictures, and their differential diagnosis is often difficult when based only on clinical images. Pancreatic head cancer and bile duct cancer account for the most cases of malignant biliary strictures. The histologic diagnosis of pancreatic head cancer is often confirmed with endoscopic ultrasound-guided fine-needle aspiration (EUSFNA), whereas pathologic evidence for bile duct cancer is usually obtained from standard endoscopic trans-papillary tissue samplings, such as cytology and forceps biopsy. However, an increase in the number of cases of benign biliary stricture masquerading as biliary carcinoma has recently been indicated [1-4]. Many of these studies report that even after diagnostic attempts with cytopathologic examinations, surgical resection is still performed. Therefore, better accuracy is needed for biliary cytology. benign cases. The sensitivity of cytology was significantly higher with post-brushing lavage fluid than with the other three sampling methods $(P<$ 0.0001 ), and post-brushing lavage fluid improved the cumulative sensitivity by $24 \%(P=0.002)$. The sensitivity of biliary cytology was also associated with the amount of aspirated bile $(P=0.01)$ and with the aspiration site $(P=0.03)$. The rate of cancer positivity in a cytology set differed according to the tumor macroscopic type (85\% in the protruding type vs. $40 \%$ in the flat type; $P=0.003$ ), and according to the size of the cancer ( $87 \%$ for tumors $\geq 50 \mathrm{~mm}$ vs. $66 \%$ for tumors $<50 \mathrm{~mm}$; $P=$ 0.02 ).

Conclusions: Post-brushing biliary lavage fluid cytology provides superior diagnostic efficacy, and its addition to ERCP procedures is recommended for obtaining cytologic evidence of bile duct cancer.

Endoscopic retrograde cholangiopancreatography (ERCP) conducted for biliary drainage can easily incorporate biliary cytology, but only a few sampling methods have been reported [5 - 7] for a small number of cases. The use of a brush can improve the diagnostic ability of biliary cytology by providing samples such as brush smears and brush-rinsed saline. However, even with this type of sample, the sensitivity for the diagnosis of bile duct cancer is generally unsatisfactory $(23 \%-63 \%)$ [8-12]. In addition, most of the previous studies were conducted without the availability of surgical samples, so the cytologic analysis was not compared with the pathologic findings in the resected biliary cancers.

In the present study, we analyzed the biliary cytology of a large number of bile duct cancers and compared the efficacy of biliary cytology for four types of biliary sampling methods: simple aspiration of bile, two stricture-scraping brush methods (brush smear and brush-rinsed saline), and a no- 
Table 1 Characteristics of the patients enrolled in a study of the sensitivity of bile cytology in the diagnosis of bile duct cancer.

\begin{tabular}{|lllll|}
\hline Diagnosis & Patients, $\mathbf{n}$ & Male patients, $\mathbf{n}$ & Median age (range), $\mathbf{y}$ & Median follow-up (range), mo \\
\hline Bile duct cancer & 76 & 62 & $70(48-83)$ & - \\
\hline Hilar bile duct cancer & 41 & 34 & $70(56-83)$ & - \\
\hline Common bile duct cancer & 35 & 28 & $71(48-80)$ & - \\
\hline Benign bile duct stricture & 50 & 42 & $67(45-84)$ & $40(14-86)$ \\
\hline AIP-SC & 33 & 28 & $65(45-84)$ & $43(14-77)$ \\
\hline Choledocholithiasis & 11 & 9 & $67(61-81)$ & $36(20-86)$ \\
\hline Sclerosing cholangitis & 4 & 3 & $75(71-82)$ & $19(14-59)$ \\
\hline Stricture of hepaticojejunostomy & 2 & 2 & $72(66-78)$ & $54(51-57)$ \\
\hline
\end{tabular}

AIP-SC, sclerosing cholangitis associated with autoimmune pancreatitis.

vel sampling of post-brushing biliary lavage fluid. The cytologic efficacy was also compared with the sampling and pathologic factors determined in the resected materials from the same cases.

\section{Patients and methods}

$\nabla$

This was a single-center retrospective study. We retrospectively investigated the diagnostic sensitivity, specificity, positive predictive value (PPV), negative predictive value (NPV), and accuracy of the biliary cytology obtained with each sampling method. Demographic factors, sampling-related factors (amount of aspirate and site of aspiration), and tumor pathologic factors were analyzed for their association with the efficacy of biliary cytology.

\section{Patients}

The present study retrospectively investigated 76 patients with bile duct cancer who underwent all four types of biliary sampling methods and surgery at the Shizuoka Cancer Center between January 2008 and July 2013 ( $\odot$ Table 1 ). The study also included 50 patients with benign biliary stricture as a control group (33 with autoimmune pancreatitis-associated sclerosing cholangitis [AIPSC], 11 with benign biliary stricture with choledocholithiasis, 4 with primary sclerosing cholangitis or immunoglobulin G4 (IgG4)-related sclerosing cholangitis, 2 with benign biliary anastomosis at a hepaticojejunostomy). All cases of bile duct cancer were diagnosed pathologically by mapping thin-sliced resected specimens and were evaluated for their pathologic factors. A final diagnosis of AIP-SC was based on the 2006 Japanese clinical diagnostic criteria for autoimmune pancreatitis [13]. IgG4-related sclerosing cholangitis was diagnosed based on the clinical diagnostic criteria of IgG4-related sclerosing cholangitis 2012 [14]. Furthermore, all patients with benign bile duct stricture were followed up for at least 1 year after ERCP, and a clinical course without any sign of disease progression was noted.

\section{ERCP tissue sampling techniques}

The procedures for collecting cytologic samples from the bile duct were as follows ( $\bullet$ Fig. $\mathbf{1}$ ). After the patient had fasted for more than 7 hours, a side-viewing duodenoscope (JF240, JF260V, or TJF260V; Olympus, Tokyo, Japan) was advanced to the descending portion of the duodenum and the view was adjusted toward the major papilla. After the placement of a cannula (tapered type; MTW Co., Düsseldorf, Germany) and confirmation of the bile duct with a very small amount $(<1 \mathrm{~mL})$ of contrast medium, bile was aspirated as an initial sample for cytology (aspirated bile). Routine cholangiography was then performed, after which a disposable 2-mm cytology brush (BC-24Q; Olympus) (৫ Fig. 1) was inserted along a 0.035-inch guidewire (Hydra Jag- wire; Boston Scientific, Natick, Massachusetts, USA) and vibrated within the stricture at least 30 times to scrape the biliary surface tissues. The tip of the brush was then rubbed onto a slide glass, and the sample on the slide was immediately fixed in $100 \%$ ethanol (brush smear). The brush was thoroughly washed in $10 \mathrm{~mL}$ of physiologic saline, and the saline was used as a third sample (brush-washed saline or brush-rinsed saline). Finally, after the brushing, the biliary lumen was washed with approximately 5 to $15 \mathrm{~mL}$ of physiologic saline, which was then re-collected via the outer sheath of the brush (post-brushing biliary lavage fluid). In patients with symptoms of cholangitis (fever, abdominal pain, high white blood cell count, tachycardia, decreased blood pressure), we washed the biliary lumen with $5 \mathrm{~mL}$ of physiologic saline. Otherwise, we washed with approximately $15 \mathrm{~mL}$ of physiologic saline. Finally, the aspirated bile, brush smear, brush-rinsed saline, and post-brushing biliary lavage fluid samples were examined cytologically for 76 patients with bile duct cancer and for $49,25,25$, and 17 patients, respectively, with benign bile duct stricture.

\section{Grading of biliary cytology}

All specimens were stained with Papanicolaou solution and rated as class I to V. Cytologic findings considered suggestive of malignancy were the following: irregularly arranged nuclei, irregular margins for clusters, enlarged nuclei, irregularly shaped nuclei, and abnormal chromatin $[15,16]$. Other notable findings were a necrotic background and cell clusters of different sizes. The biliary cytology was graded according to the combinations of these cytologic findings. The diagnostic grading system used in the present study was as follows: inadequate; benign (class I) ( $\odot$ Fig. 2a); atypical cells present (class II); suspicious for cells from a neoplastic lesion (class III) ( $\bullet$ Fig. 2 b); strongly suspicious for malignancy (class IV); and definitely malignant (class V) $(\Theta \mathrm{Fig} .2 \mathrm{c}$ ). In this study, classes I through III were regarded as benign, and classes IV and V as malignant (positive for cancer). Cytologic evaluation was performed before the surgical resection in all cases by a single specialist (K. S., listed as a co-author) in the field of hepatico-biliary-pancreatic pathology.

\section{Pathologic diagnosis of the surgical specimen}

We analyzed the following pathologic factors affecting the efficacy of biliary cytology in 76 patients with surgically resected biliary cancer: location, size, macroscopic type, differentiation, depth of invasion, lymph duct permeation, venous permeation, lymph node metastasis, and invasion of adjacent organs (liver, gallbladder, and pancreas) [17]. The classification of the Japanese Society of Biliary Surgery [17] was used to categorize the macroscopic appearance of the bile duct cancers as papillary type, nodular type, or flat type. Cancers of the papillary type and nodular 


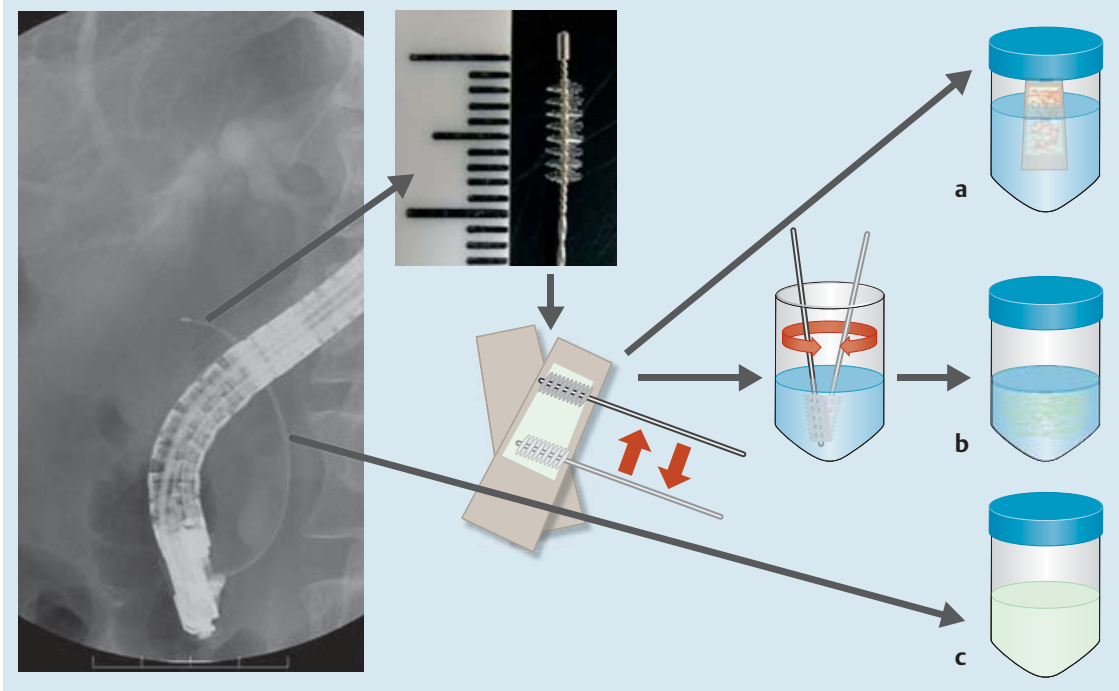

Fig. 1 Samples for biliary cytology are collected with a brush following bile aspiration. This technique is useful in the diagnosis of bile duct cancer. a Smear from the brush is placed between a pair of slide glasses and preserved in 100\% alcohol (brush smear). b Biliary epithelial cells are exfoliated from the brush by stirring in up to $10 \mathrm{~mL}$ of saline (brushrinsed saline). c Fluid collected from the bile duct lumen after brushing and injection of 5 to $15 \mathrm{~mL}$ of saline (post-brushing biliary lavage fluid).
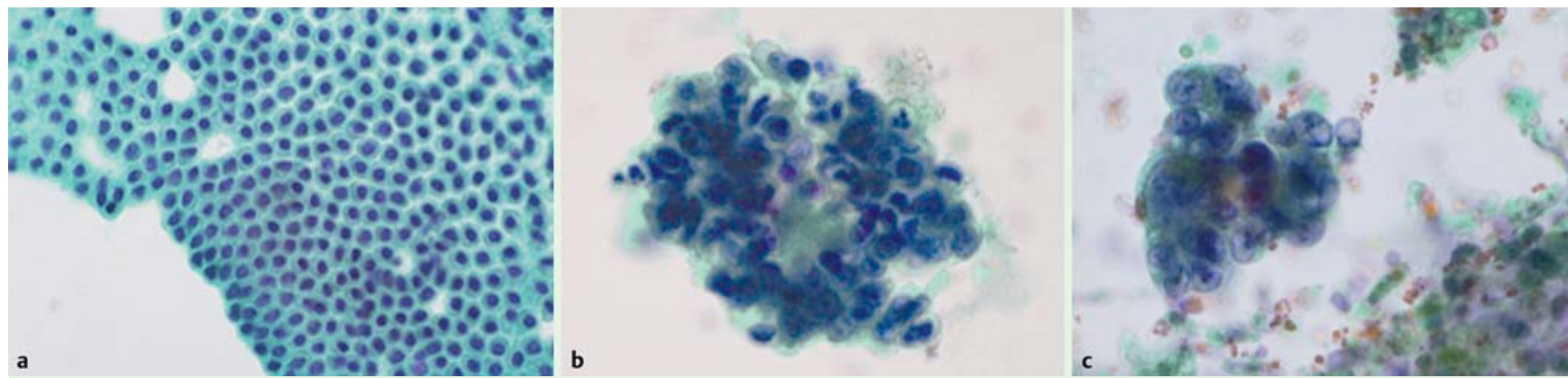

Fig. 2 Cytologic views of post-brushing biliary lavage fluid (Papanicolaou stain, original magnification $\times 400$ ). a Normal biliary epithelial cells (class I) appearing as a sheet of benign epithelium. The sheet consists of regularly ordered, homogeneous cuboidal cells. $\mathbf{b}$ Benign biliary epithelial cells with cellular atypia (class III) appearing as a cluster of inflammatory cells and epithelial cells with enlarged nuclei and architectural disorganization. c A cluster of adenocarcinoma cells (class V) appearing as nested epithelial cells with significantly enlarged nuclei and irregular nuclear margins.

type were grouped as protruding type. Tumor size, measured pathologically, included areas showing intramucosal (intraepithelial) spread of carcinoma, not just invasive cancer.

\section{Statistical analyses}

Factors possibly affecting cytologic sensitivity were first analyzed by univariate analysis with Fisher's exact test and Wilcoxon's rank sum test. The candidate factors were then re-analyzed by multivariate analysis with logistic regression analysis. All data analysis was performed with R Statistical Software, and a $P$ value of less than 0.05 was considered statistically significant.

\section{Results}

\section{$\boldsymbol{\nabla}$}

\section{Biliary cytology by each sampling method}

Biliary cytology was analyzed by each sampling method in 76 patients with bile duct cancer and in 50 patients with benign biliary cytology ( Table 2 ). The sensitivity of detecting bile duct cancer was 34\% (26/76) with aspirated bile, 32\% (24/76) with brush smear, 43\% (33/76) with brush-rinsed saline, and 70\% (53/76) with post-brushing biliary lavage fluid. A significant difference was noted between the sensitivity of cytology with post-brushing biliary lavage fluid and the other sampling methods $(P<$ 0.0001 vs. aspirated bile and vs. brush smears; $P=0.001$ vs. brush-rinsed saline). Post-brushing biliary lavage fluid cytology added $24 \%(18 / 76)$ to the sensitivity in comparison with the cu- mulative results obtained with the other three cytologic methods $(P=0.002)$ ( Table 2$)$. None of the samples obtained from the benign biliary strictures showed malignant cells, regardless of the sample type (100\% specificity). The accuracy of cytology was best with post-brushing biliary lavage fluid (75\%), and it was significantly higher than the accuracy obtained with aspirated bile (60\%; $P=0.02$ ), brush-rinsed saline (57\%; $P=0.01$ ), or brush smears (49\%; $P=0.0002)$ ( $\bullet$ Table 2).

\section{Technical factors affecting the efficacy of biliary cytology}

We considered that some of the technical aspects of biliary sampling, such as amount of aspirate and site of aspiration, might affect the efficacy of biliary cytology ( $\bullet$ Table 3 ). Data on aspirate amount were available for 75 cases of aspirated bile and for 67 cases of post-brushing biliary lavage fluid, and data on the aspiration site were available for 75 cases of aspirated bile and for 75 cases of post-brushing biliary lavage fluid. Cases without the records for these data were excluded from this analysis. The receiver operating characteristic curve analysis indicated that the required amount of aspirate was $10 \mathrm{~mL}$ for aspirated bile and $20 \mathrm{~mL}$ for post-brushing biliary lavage fluid. The sensitivity of detecting cancer cells in $10 \mathrm{~mL}$ or more of aspirated bile (52\%, 12 of 23 cases) was significantly higher than the sensitivity in less than $10 \mathrm{~mL}$ (27\%, 14 of 52 cases; $P=0.03$ ) ( Table 3 ). The sensitivity of post-brushing biliary lavage fluid did not significantly differ according to the aspirate amount $(80 \%$ in $\geq 20 \mathrm{~mL}$ vs. $65 \%$ in 
Table 2 Sensitivity of biliary cytology by sampling step $(n=76){ }^{1}$

\begin{tabular}{|c|c|c|c|c|c|c|}
\hline Sample & $\begin{array}{l}\text { Median amount of } \\
\text { specimen (range), } \mathrm{mL}\end{array}$ & Sensitivity, \% (n) & $\begin{array}{l}\text { Cumulative } \\
\text { sensitivity, \% (n) }\end{array}$ & PPV, \% (n) & NPV, \% (n) & Accuracy, \% (n) \\
\hline Aspirated bile & $5(1-40)$ & $34^{\mathrm{a} 2}(26 / 76)$ & $34^{\mathrm{e} 2}(26 / 76)$ & $100(26 / 26)$ & 49 (49/99) & $60^{\mathrm{i} 3}(75 / 125)$ \\
\hline Brush smear & - & $32^{\mathrm{b2}}(24 / 76)$ & $45^{f 2}(34 / 76)$ & $100(24 / 24)$ & $32(25 / 77)$ & $49^{\mathrm{j} 4}(49 / 101)$ \\
\hline Brush-rinsed saline & - & $43^{c 5}(33 / 76)$ & $55^{96}(42 / 76)$ & $100(33 / 33)$ & $37(25 / 68)$ & $57^{k 7}(58 / 101)$ \\
\hline $\begin{array}{l}\text { Post-brushing biliary } \\
\text { lavage fluid }\end{array}$ & $7.5(2-40)$ & $70^{d}(53 / 76)$ & $79^{h}(60 / 76)$ & $100(53 / 53)$ & $43(17 / 40)$ & $75^{\prime}(70 / 93)$ \\
\hline
\end{tabular}

PPV, positive predictive value; NPV, negative predictive value.

${ }^{1}$ This analysis was done in 76 patients who underwent all four types of biliary sampling.

2 a vs. d, b vs. d, e vs. h, f vs. h: $P<0.0001$.

${ }^{3}$ i vs. I: $P=0.02$.

${ }^{4}$ j vs. I: $P=0.0002$

${ }^{5}$ c vs. d: $P=0.001$

${ }^{6} \mathrm{~g}$ vs. h: $P=0.002$

7 k vs. I: $P=0.01$

Table 3 Technical factors affecting the sensitivity of biliary cytology.

\begin{tabular}{|c|c|c|c|c|}
\hline Samples & Technical factor & Condition & Sensitivity, \% (n) $)^{1}$ & $P$ value \\
\hline Aspirated bile & Fluid amount & $\begin{array}{l}\geq 10 \mathrm{~mL} \\
<10 \mathrm{~mL}\end{array}$ & $\begin{array}{l}52(12 / 23) \\
27(14 / 52)\end{array}$ & 0.03 \\
\hline Post-brushing biliary lavage fluid & Fluid amount & $\begin{array}{l}\geq 20 \mathrm{~mL} \\
<20 \mathrm{~mL}\end{array}$ & $\begin{array}{l}80(12 / 15) \\
65(34 / 52)\end{array}$ & 0.36 \\
\hline Aspirated bile & Aspiration site & $\begin{array}{l}\text { Across the tumor } \\
\text { Upstream only }\end{array}$ & $\begin{array}{l}33(16 / 49) \\
38(10 / 26)\end{array}$ & 0.61 \\
\hline Post-brushing biliary lavage fluid & Aspiration site & $\begin{array}{l}\text { Across the tumor } \\
\text { Upstream only }\end{array}$ & $\begin{array}{l}75(36 / 48) \\
59(16 / 27)\end{array}$ & 0.16 \\
\hline
\end{tabular}

${ }^{1}$ Amount and site of the aspiration were not completely recorded; therefore, the number was inconsistent and the statistics were obtained only by univariate analysis.

$<20 \mathrm{~mL} ; P=0.36)$. The sensitivity of detecting cancer cells in aspirated bile did not differ according to the aspiration site (38\% when bile was aspirated only at the upstream region and 33\% when it was aspirated across the tumor; $P=0.61$ ). The sensitivity of detecting cancer cells in post-brushing lavage fluid also did not differ according to the aspiration site (59\% when bile was aspirated only at the upstream region and $75 \%$ when it was aspirated across the tumor; $P=0.16$ ). The aspiration site has no effect ( Table 3).

\section{Demographic factors and tumor factors affecting the efficacy of biliary cytology}

We analyzed the patients' demographic factors (age and sex) and the tumor pathologic factors (macroscopic type, size, location, differentiation, depth of invasion, differentiation, and invasion of adjacent organs) for any association with the cumulative sensitivity of biliary cytology ( 0 Table 4). No association was recognized between the patients' demographics and biliary cytology, but some tumor factors were associated with the sensitivity of biliary cytology. The univariate analysis showed that the sensitivity was significantly higher in protruding-type tumors $(85 \%, 56$ / $66)$ than in flat-type tumors $(40 \%, 4 / 10 ; P=0.004)$. The sensitivity also correlated with tumor size (tumor size $<50 \mathrm{~mm}$ : 87\% [41/47] and tumor size $\geq 50 \mathrm{~mm}: 66 \%$ [19/29]; $P=0.04$ ). The sensitivity of biliary cytology tended to be higher in cases of hepatic hilar cancer $(88 \%, 36 / 41)$ than in cases of extrahepatic cancer $(69 \%, 24$ / $35)$; however, the difference was not statistically significant $(P=$ 0.051). The depth of invasion and the differentiation level were not associated with the cytologic efficacy ( $\bullet$ Table 4). Pathologic factors such as lymph duct permeation, venous permeation, lymph node metastasis, and invasion of the adjacent organs (liver, gallbladder, and pancreas) were not associated with the sensitivity of cytology (data not shown).

\section{Adverse events}

No obvious adverse events, such as biliary hemorrhage and perforation, were noted for the brushing procedures in any of the cases.

\section{Take-home message}

The aim of this study was to reveal the usefulness of post-brushing biliary lavage fluid cytology in the diagnosis of cholangiocarcinoma. The biliary lavage method demonstrated a significantly higher sensitivity (70\%) than standard biliary cytology with aspirated bile (34\%) and/or brushing samples (32\% and $43 \%)$. The amount of aspirate, tumor size (including intramucosal spread), and macroscopic tumor type all affected the efficacy of biliary cytology.

\section{Discussion}

This study demonstrated a high sensitivity (79\%) and specificity $(100 \%)$ for the cumulative results obtained with four cytologic techniques. Post-brushing biliary lavage fluid cytology added $24 \%(18 / 76)$ to the sensitivity compared with the cumulative results obtained with the other three cytologic techniques $(P=$ 0.002 ) ( Table 2). This sensitivity was higher than previously reported values $(23 \%-63 \%)$ [8-12]. However, simple comparison of sensitivities among different institutions does not provide an objective evaluation of a methodology because of the wide range of interobserver variation that has been reported in the cytologic and pathologic diagnosis of disease in many organs $[16,18-21]$. This diagnostic disagreement is associated with the experience [18] and institution type [19] of the pathologists and with the pathologic type of tumor [20]. Discordances in cytopathologic criteria are seen even among different nations $[22,23]$. 


\begin{tabular}{|c|c|c|c|c|c|c|}
\hline \multirow[t]{2}{*}{ Factor } & \multirow[t]{2}{*}{ Condition } & \multirow[t]{2}{*}{ Sensitivity, \% (n) } & \multirow[t]{2}{*}{ OR } & \multirow[t]{2}{*}{$95 \% \mathrm{Cl}$} & \multicolumn{2}{|l|}{$P$ value } \\
\hline & & & & & Univariate & Multivariate \\
\hline \multicolumn{7}{|l|}{ Demographics } \\
\hline \multirow[t]{2}{*}{ Age, $y$} & $\geq 70$ & $79(34 / 43)$ & 1 & $0.35-3.01$ & 1 & 0.41 \\
\hline & $<70$ & $79(26 / 33)$ & & & & \\
\hline \multirow[t]{2}{*}{ Gender } & Male & $77(48 / 62)$ & 0.6 & $0.13-2.60$ & 0.72 & 0.82 \\
\hline & Female & $86(12 / 14)$ & & & & \\
\hline \multicolumn{7}{|l|}{ Tumor } \\
\hline \multirow{2}{*}{ Macroscopic type } & Protruding & $85(56 / 66)$ & 8.4 & $2.12-33.22$ & 0.004 & 0.003 \\
\hline & Flat & $40(4 / 10)$ & & & & \\
\hline \multirow[t]{2}{*}{ Size, mm } & $\geq 50$ & $87(41 / 47)$ & 3.6 & $1.17-10.99$ & 0.04 & 0.02 \\
\hline & $<50$ & $66(19 / 29)$ & & & & \\
\hline \multirow[t]{2}{*}{ Location } & Hepatic hilar & $88(36 / 41)$ & 3.3 & $1.05-10.27$ & 0.051 & 0.12 \\
\hline & Extrahepatic & $69(24 / 35)$ & & & & \\
\hline \multirow[t]{2}{*}{ Depth of invasion } & $\mathrm{m}, \mathrm{fm}$ & $83(5 / 6)$ & 1.4 & $0.19-9.32$ & 1 & 0.81 \\
\hline & ss, se & $79(55 / 70)$ & & & & \\
\hline \multirow[t]{2}{*}{ Differentiation } & Good, moderate & $79(3 / 4)$ & 0.8 & $0.10-5.83$ & 1 & 0.51 \\
\hline & Poor & $75(57 / 72)$ & & & & \\
\hline
\end{tabular}

OR, odds ratio; $\mathrm{Cl}$, confidence interval; $\mathrm{m}$, mucosal; fm, fibromuscular; ss, subserosal; se, exposed to serosa.

${ }^{1}$ This analysis was done in 76 patients who underwent all four types of biliary sampling.

This is also true in the field of biliary cytology for the diagnosis of bile duct cancer, in which a rate of interobserver agreement of $48 \%$ to $52 \%$ was reported in a previous study $(k=0.66)$ [21]. We therefore performed a more objective analysis by sampling the bile of 76 patients with biliary cancer and comparing the diagnostic efficacy of four types of biliary sampling. Post-brushing biliary lavage fluid cytology (70\%) demonstrated more than twice the sensitivity of aspirated bile cytology (34\%) and added a further $24 \%$ to the cumulative sensitivity of the other three sampling methods ( $\bullet$ Table 2 ).

Several methodologic devices have been reported for the improvement of biliary cytology based on the aspects of sampling, cytopreparation [24], and molecular approach [25 - 27]. A brush $[15,28]$ is the most common sampling device used in the daily clinic, and a more cellular sample is usually obtained with brushing than with direct bile sampling as a consequence of traumatization of the ductal epithelium through contact with the abrasive bristles of the brush. Although the specificity is high, the sensitivity for the detection of malignancy remains unsatisfactory $(23 \%-$ $63 \%)[8-12,15,28]$. The use of a larger cytology brush $(3 \mathrm{~mm} \times$ $5 \mathrm{~cm}$ ) increased the cellularity but did not improve the cancer detection rate over that obtained with a standard brush [9]. The combination of biliary dilation, endoscopic needle aspiration, and subsequent brushing cytology showed a higher sensitivity (85\%) than brushing alone (57\%; $P<0.02)$ [29].

The use of a liquid-based cytopreparation, or ThinPrep [15, 16], improved interobserver agreement regarding cytologic features for diagnosing malignancy. In molecular diagnostic approaches, reported by Krishnamurthy et al. [25], DNA histograms decreased the false-negative rate of biliary cytology by $7 \%$, while DNA hyperploidy (DNA content $>5 \mathrm{c}$ ) diagnosed bile duct cancer with $62 \%$ sensitivity and $91 \%$ specificity. Kipp et al. [26] used fluorescence in situ hybridization (FISH) on chromosomes 3, 7, 9 , and 17 to evaluate biliary brushing samples obtained from biliary strictures and reported $34 \%$ sensitivity for detecting cancer by FISH and $15 \%$ by cytology $(P<0.01)$. In the current study, the evaluation of post-brushing biliary lavage fluid, which can be collected in 1 minute by washing the biliary lumen with saline, demonstrated a significant improvement in biliary cytology without adverse events. These other molecular methods, if com- bined with the use of post-brushing biliary lavage fluid, may result in even greater improvements in sensitivity to an excellent level.

In the current study, the size and macroscopic appearance of the cancer were strongly correlated with the efficacy of biliary cytology ( $\checkmark$ Table 4). The theoretical mechanism to explain the effectiveness of the biliary lavage method is that the coupling of exfoliation of the epithelial cells by brush stimulation and lavage of the biliary surface with saline increases the chance of collecting malignant cells via the catheter ( Table 2 ). If this is the case, then the amount of superficial spread of intramucosal carcinoma is important for this cytology, but the invasiveness of the cancer is not. The pathologic observation of 253 resected cases showed that the mucosal extension of carcinoma over a macroscopic mass was observed in $47 \%$ to $48 \%$ of cases of biliary cancer, with a median length of $10 \mathrm{~mm}$ from the invasive margin [30]. The characteristics of biliary cancer with widely spreading intramucosal carcinoma were macroscopically protruding type, less advanced stage, slower growth, and better prognosis [31]. Conversely, flat invasive cancers with minimal mucosal spreading, which are associated with aggressive biological behavior, are difficult to detect with biliary cytology ( $\bullet$ Table 4$)$.

Clinicopathologic studies of benign biliary strictures masquerading as biliary carcinoma are being increasingly reported [1-4]. Even with cytopathologic examination or demonstration of the known features of benign disease, resection continues to be performed because of the suspicion of a hidden biliary cancer. Avoiding these unnecessary surgeries and ensuring the timing of curable treatment will require improvements in biliary cytology in future studies.

\section{Competing interests: None}

\footnotetext{
Institutions

${ }^{1}$ Division of Endoscopy, Shizuoka Cancer Center, Shizuoka, Japan

2 Division of Molecular Biology and Biochemistry, Graduate School of Medicine, Osaka University, Osaka, Japan

${ }^{3}$ Division of Pathology, Shizuoka Cancer Center, Shizuoka, Japan

${ }^{4}$ Division of Hepato-Biliary-Pancreatic Surgery, Shizuoka Cancer Center, Shizuoka, Japan

Division of Clinical Trials, Shizuoka Cancer Center, Shizuoka, Japan
} 


\section{References}

1 Corvera CU, Blumgart LH, Darvishian F et al. Clinical and pathologic features of proximal biliary strictures masquerading as hilar cholangiocarcinoma. J Am Coll Surg 2005; 201: $862-869$

2 Erdogan D, Kloek JJ, ten Kate FJ et al. Immunoglobulin G4-related sclerosing cholangitis in patients resected for presumed malignant bile duct strictures. Br J Surg 2008; 95: 727-734

3 Fujita T, Kojima M, Gotohda $N$ et al. Incidence, clinical presentation and pathological features of benign sclerosing cholangitis of unknown origin masquerading as biliary carcinoma. J Hepatobiliary Pancreat Surg 2010; 17: 139-146

4 Matsubayashi H, Uesaka K, Sugiura T et al. IgG4-related sclerosing cholangitis without obvious pancreatic lesion: difficulty in differential diagnosis. J Dig Dis 2014; 15: 394 - 403

5 Farrell RJ, Jain AK, Brandwein SL et al. The combination of stricture dilation, endoscopic needle aspiration, and biliary brushings significantly improves diagnostic yield from malignant bile duct strictures. Gastrointest Endosc 2001; 54: 587-594

6 Curcio G, Traina M, Mocciaro $F$ et al. Intraductal aspiration: a promising new tissue-sampling technique for the diagnosis of suspected malignant biliary strictures. Gastrointest Endosc 2012; 75: 798 - 804

7 Fogel EL, deBellis M, McHenry L et al. Effectiveness of a new long cytology brush in the evaluation of malignant biliary obstruction: a prospective study. Gastrointest Endosc 2006; 63: 71 - 77

8 Jailwala J, Fogel EL, Sherman $S$ et al. Triple-tissue sampling at ERCP in malignant biliary obstruction. Gastrointest Endosc 2000; 51: 383-390

9 Fogel EL, deBellis M, McHenry L et al. Effectiveness of a new long cytology brush in the evaluation of malignant biliary obstruction: a prospective study. Gastrointest Endosc 2006; 63: 71 -77

10 Ponchon T, Gagnon P, Berger F et al. Value of endobiliary brush cytology and biopsies for the diagnosis of malignant bile duct stenosis: results of a prospective study. Gastrointest Endosc 1995; 42: 565-572

11 Mansfield JC, Griffin SM, Wadehra V et al. A prospective evaluation of cytology from biliary strictures. Gut 1997; 40: 671-677

12 Sugiyama M, Atomi $Y$, Wada $\mathrm{N}$ et al. Endoscopic transpapillary bile duct biopsy without sphincterotomy for diagnosing biliary strictures: a prospective comparative study with bile and brush cytology. Am J Gastroenterol 1996; 91: 465-467

13 Okazaki K, Kawa S, Kamisawa T et al. Clinical diagnostic criteria of autoimmune pancreatitis: revised proposal. J Gastroenterol 2006; 41: $626-631$

14 Ohara $\mathrm{H}$. Clinical diagnostic criteria of IgG4-related sclerosing cholangitis 2012. J Hepatobiliary Pancreat Sci 2012; 19: 536-542

15 Selvaggi SM. Biliary brushing cytology. Cytopathology 2004; 15: $74-$ 79

16 Waugh MS, Guy CD, Maygarden SJ et al. Use of the ThinPrep method in bile duct brushings: analysis of morphologic parameters associated with malignancy and determination of interobserver reliability. Diagn Cytopathol 2008; 36: $651-656$

17 Japanese Society of Biliary Surgery. Classification of biliary tract carcinoma. 2nd: English edn. Tokyo, Japan: Kanehara; 2004

18 Darragh TM, Winkler B, Souers RJ et al. Room for improvement: initial experience with anal cytology: observations from the College of American Pathologists interlaboratory comparison program in nongynecologic cytology. Arch Pathol Lab Med 2013; 137: 1550 - 1554

19 Raitanen MP. Aine R, Rintala E et al. Differences between local and review urinary cytology in diagnosis of bladder cancer. An interobserver multicenter analysis. Eur Urol 2002; 41: $284-289$

20 Kummerlin IP, Smedts F, ten Kate FJ et al. Cytological punctures in the diagnosis of renal tumours: a study on accuracy and reproducibility. Eur Urol 2009; 55: 187-195

21 Harewood GC, Baron TH, Stadheim LM et al. Prospective, blinded assessment of factors influencing the accuracy of biliary cytology interpretation. Am J Gastroenterol 2004; 99: 1464-1469

22 Schlemper RJ, Itabashi $M$, Kato $Y$ et al. Differences in diagnostic criteria for gastric carcinoma between Japanese and Western pathologists. Lancet 1997; 349: 1725-1729

23 Schlemper RJ, Riddell RH, Kato $Y$ et al. The Vienna classification of gastrointestinal epithelial neoplasia. Gut 2000; 47: 251-255

24 Ylagan LR, Liu LH, Maluf HM. Endoscopic bile duct brushing of malignant pancreatic biliary strictures: retrospective study with comparison of conventional smear and ThinPrep techniques. Diagn Cytopathol 2003; 28: 196-204

25 Krishnamurthy S, Katz RL, Shumate A et al. DNA image analysis combined with routine cytology improves diagnostic sensitivity of common bile duct brushing. Cancer 2001; 93: 229-235

26 Kipp BR, Stadheim LM, Halling SA et al. A comparison of routine cytology and fluorescence in situ hybridization for the detection of malignant bile duct strictures. Am J Gastroenterol 2004; 99: 16751681

27 Ito $H$, Satoh $K$, Hamada $S$ et al. The evaluation of MSX2 mRNA expression level in biliary brush cytological specimens. Anticancer Res 2011; 31: $1011-1017$

28 Chadwick BE. Beyond cytomorphology: expanding the diagnostic potential for biliary cytology. Diagn Cytopathol 2012; 40: 536-54129

29 Farrell RJ, Jain AK, Brandwein SL et al. The combination of stricture dilation, endoscopic needle aspiration, and biliary brushings significantly improves diagnostic yield from malignant bile duct strictures. Gastrointest Endosc 2001; 54: 587-594

30 Ebata T, Watanabe H, Ajioka $Y$ et al. Pathological appraisal of lines of resection for bile duct carcinoma. Br J Surg 2002; 89: 1260-1267

31 Igami T, Nagino M, Oda K et al. Clinicopathologic study of cholangiocarcinoma with superficial spread. Ann Surg 2009; 249: 296-302 